\title{
Heat transfer enhancement for PCM-based heat storage with plate fins
}

\author{
BinbinKe $^{a}$, Xinnan Song ${ }^{b}$
}

School of energy and power engineering,Jiangsu University,Zhenjiang,Jiangsu,212013, China

ake.bin.bin@163.com, beksen@ujs.edu.cn

Keywords:PCM, numerical simulation, heat storage, heat transfer enhancement.

\begin{abstract}
The low thermal conductivity of phase change material (PCM) is the main resistance of heat transfer in latent storage system. Characterization of melting process in a PCM-based heat sink with plate fin type thermal conductivity enhancers is numerically studied in this paper. Detailed parametric investigations of plate fins are performed to find the effect on melting time. The results showed that decreasing the pitch of fins resulted in an appreciable increase in overall thermal performance. Increasing the fin thickness and conductivity only gave a slight improvement.
\end{abstract}

\section{Introduction}

Thermal energy storage plays an important role in some industrial applications, such as, solar thermal storage[1,2], air conditioning, energy-saving building [3,4]and waste heat recovery systems. Thermal energy storage systems are crucial for reducing dependency on fossil fuels and also for minimizing $\mathrm{CO}_{2}$ emissions. Thermal energy storage can be accomplished either by using sensible heat storage or latent heat storage. Sensible heat storage has been used for centuries by builders to store/release passively thermal energy, but a much larger volume of material is required to store the same amount of energy in comparison to latent heat storage[5]. Latent heat storage is more attractive than sensible heat storage because of its high storage density with smaller temperature swing [6]. During melting or solidification processes, a PCM (phase change material) can effectively release or store a significant amount of latent heat. The temperature of a PCM can also be stably maintained during the latent heat transfer process. Therefore, a PCM is a very promising material choice in energy storage and thermal environmental control applications. However, nearly all organic PCMs have unacceptably low thermal conductivity which makes it difficult to utilize the heat storage capacity completely $[7,8]$. The rate of heat transfer can be enhanced by incorporating high thermal conductivity materials, known as thermal conductivity enhancer (TCE) into the PCM. TCE is distributed in the PCM in the form of metal matrix, fins and uniformly dispersed high thermal conductivity particles $[9,10]$.

In the present paper, characterization of melting process in a plate fine type PCM-based heat storage heated uniformly from the bottom is presented. The enclosure is the space enclosed by two fins and the base plate of the heat sink. The objective is to investigate the effect of fin parameters (fin pitch, fin thickness,fin conductivity) in heat storage on the melting time.

\section{Description of the physical problem}

A typical thermal storage unit (TSU) is shown schematically in Fig. 1 it consists of plate-fin type TCE of uniform thickness $(\delta)$ and PCM is filled in the space (D) between fins. A constant temperature, $\mathrm{T}$ is distributed uniformly at the bottom of the TSU. Fig.2 shows an elemental TSU which represents a symmetrical domain chosen for the analysis. The ratio of $\delta / \mathrm{H}$ defined as $\alpha$, which is the ratio of thickness of fin and height of fin. The ratio of $\mathrm{D} / \mathrm{H}$ is defined as $\beta$, which is the ratio of the spacing between two fins and height of fin. In this study, the height of fin $(\mathrm{H})$ of is taken as $20 \mathrm{~mm}$. Fin thickness $(\delta)$ and the spacing between two fins (D) are varied to obtain different $\beta(0.2 / 0.6 / 1 / 1.4 / 1.8)$ and $\alpha(0.04 / 0.06 / 0.08 / 0.1 / 0.14 / 0.2)$. RT50 is used as the PCM material in the present study. The thermo physical properties of RT50 and aluminum are given in Table 1. 

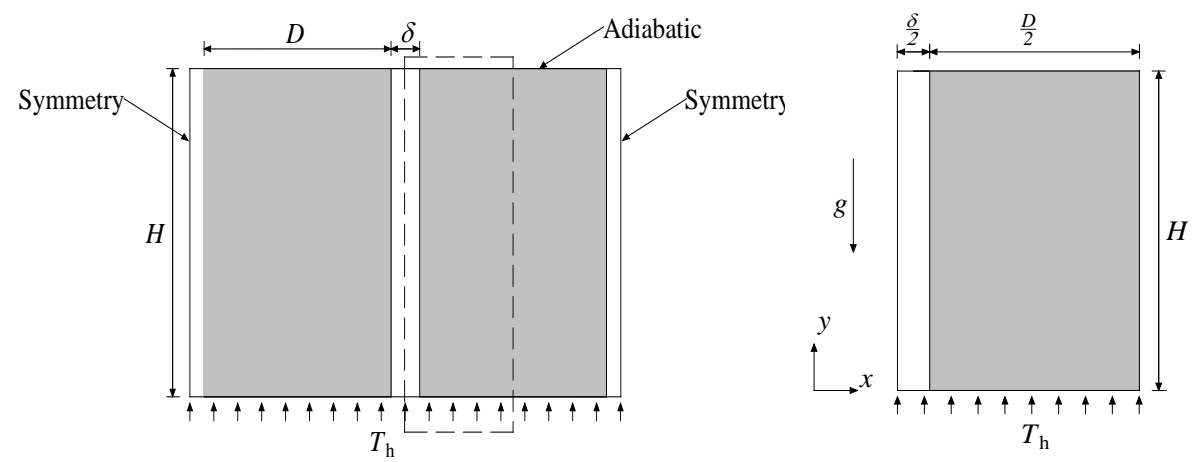

Fig.1 Physical model of a thermal storage unit Fig.2 Computational domain

Table 1 Thermo physical properties of PCM and fins

\begin{tabular}{cccccc}
\hline Materials & $\rho\left(\mathrm{kg} / \mathrm{m}^{2}\right)$ & $k(\mathrm{~W} / \mathrm{m} \cdot \mathrm{K})$ & $c_{p}(\mathrm{~J} / \mathrm{kg} \cdot \mathrm{K})$ & $T_{m}\left({ }^{\circ} \mathrm{C}\right)$ & $L(\mathrm{~kJ} / \mathrm{kg})$ \\
\hline RT50 & 780 & 0.2 & 2000 & 50 & 168 \\
Fin & 2732.1 & 200 & 960 & - & - \\
\hline
\end{tabular}

\section{Mathematical model}

\subsection{Governing equations}

A two-dimensional analysis is adopted for the plate fin type PCM-based heat storage. The fin always remains in the solid state and absorbs only sensible heat. The liquid PCM is assumed to be Newtonian and incompressible, and subjected to the Boussinesq approximation. Local thermal equilibrium between the PCM and the aluminum fins is assumed. Thermo physical properties of solid and liquid PCM remain constant over a range of temperature. The volume change of the PCM during melting/ solidification is neglected in the numerical modeling. A common set of governing conservation equations for the domain comprising of PCM and fin is given by the following:

Conservation of mass:

The mass conservation equation can be written as,

$$
\frac{\partial\left(\rho u_{i}\right)}{\partial x_{i}}=0
$$

Conservation of momentum:

The momentum conservation equation is given by:

$$
\frac{\partial\left(\rho u_{i}\right)}{\partial t}+\frac{\partial\left(\rho u_{i} u_{j}\right)}{\partial x_{j}}=-\frac{\partial P}{\partial x_{i}}+\nabla \cdot\left(\mu \nabla u_{i}\right)+S_{i}+\rho g \beta\left(T-T_{r e f}\right)
$$

Where $S_{i}$ is a flow resistance source term which is a function of solid fraction of the PCM. This source term ensures zero velocity in the fully solid region and permits normal viscous liquid flow in the fully molten region.

Energy conservation:

$$
\frac{\partial\left(\rho u_{i}\right)}{\partial t}+\frac{\partial\left(\rho u_{i} u_{j}\right)}{\partial x_{j}}=-\frac{\partial P}{\partial x_{i}}+\nabla \cdot\left(\mu \nabla u_{i}\right)+S_{i}+\rho g \beta\left(T-T_{r e f}\right)
$$

Where $S_{h}$ is the energysource term representing latent heat storagedue to melting. The conservation equations for the above transient problem are solved using a pressure-based finite volume method according to the SIMPLER algorithm.

\subsection{Boundary and initial conditions}

The temperature of the heat wall is fixed at a constant value during the melting process. The symmetry boundaries are all assumed to be adiabatic. The temperature of PCM and fin is initially set to $\mathrm{T}_{\text {ini }}$. 


\section{Results and discussion}

\subsection{Effect of fin thickness and pitch on melting}

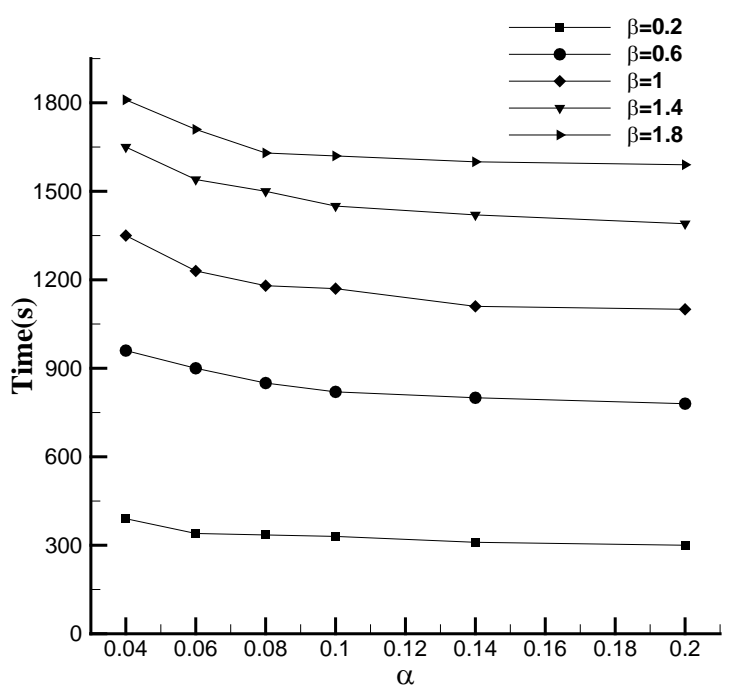

Fig.3 the effect of fin thickness and pitch on melting process

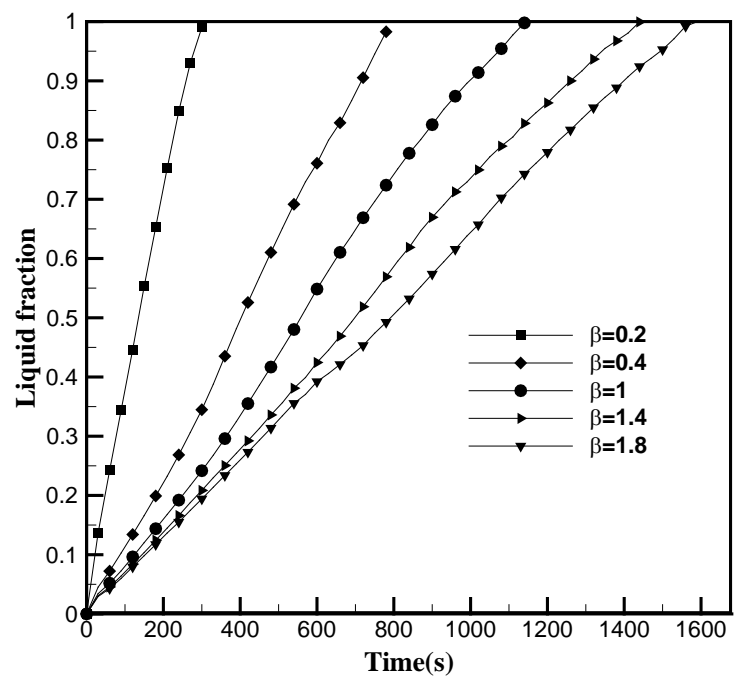

Fig.4 The liquid fraction versus time for different fin pitches

Figure 3 shows the effect of fin thickness and pitch on melting process. In this figure, the melting time decreases with increasing a in a certain range and decreases slightly with increasing $\alpha$ continually. The total heat flux from the base can be subdividedto the flux transferred into the PCM directly from the base, and the flux transferred into the PCM through the fins. For the thicker fins meltingis almost uniform along the fin surface, while for the thinner ones melting takes place mostly close to the base, which will considerably retard melting.

Figure 4 shows the case liquid fractionversus time for different fin pitches.As expected, larger pitches results in a longer melting time.Firstly, it is important to notice that the PCM RT50 has a thermalconductivity of $0.2 \mathrm{~W} / \mathrm{m} \cdot \mathrm{K}$ while the aluminum fin has a thermal conductivity of $200 \mathrm{~W} / \mathrm{m} \cdot \mathrm{K}$. This makes the fins good heat conductors while the PCM behaves almost like an insulator. Due to the low thermal conductivity of the PCM, heat is only absorbed by PCM where adjacent to heat walls. Certainly with larger pitch of two fins, the PCM away from the fin is affected little by fins.

\subsection{Effect of fin thermal conductivities on melting}

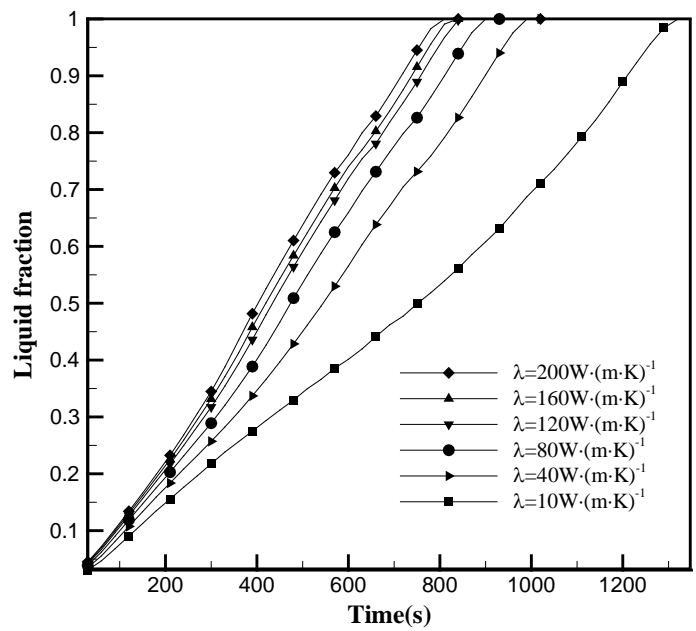

Fig. 5 the liquid fractionversus time for variousfin thermal conductivities

Figure 5 shows the liquid fractionversus time for variousfin thermal conductivities. As expected, the performance of the heat storage increases with increasing fin thermal conductivity. However, it can be seen that the $160 \mathrm{w}$ and $200 \mathrm{w}$ fin thermal conductivity give slightlybetter results. This is because of that the thermal resistance of fins reduces with largerfin thermal conductivity, which causes an increase in temperature of fins and rate of heat releases to PCM and so the overall melting 
time of heat storage decreases. It is noted that fin thermal conductivity than $160 \mathrm{w}$ do not further improve the performance of the heat storage. In other words, the fin thermal conductivity reaches it maximum performance capability at a 160w fin thermal conductivity.

\section{Conclusion}

In the present work, melting of a phase change material(PCM) in a heat storage with a constant heat temperature horizontal base and vertical internal plate fins has been studied numerically. The objective is to investigate the effect of fin parameters (fin pitch, fin thickness,fin conductivity) in heat storage on the melting time. It has been shown that the melting time decreases with increasing an in a certain range and decreases slightly with increasing a continually. Also, the larger fins pitches have a shorter melting period. It is observed that the performance of the heat storage increases with increasing fin thermal conductivity.

\section{References}

[1]. Zalba B, Marín J M, Cabeza L F, et al. Review on thermal energy storage with phase change: materials, heat transfer analysis and applications[J]. Applied thermal engineering, 2003, 23(3): 251-283..

[2]. Lane G A. Solar heat storage: latent heat materials[J]. 1983.

[3]. Peippo K, Kauranen P, Lund P D. A multicomponent PCM wall optimized for passive solar heating[J]. Energy and buildings, 1991, 17(4): 259-270.

[4]. Mehling H, Hiebler S. Review on PCM in buildings-current R\&D[J]. IEA annex, 2004, 17: 1597-1615.17 workshop in Arvika (Sweden) held on 8 June 2004. Available from /http://www.fskab.com

[5]. Soares N, Costa J J, Gaspar A R, et al. Review of passive PCM latent heat thermal energy storage systems towards buildings' energy efficiency[J]. Energy and buildings, 2013, 59: 82-103.

[6]. Kuznik F, David D, Johannes K, et al. A review on phase change materials integrated in building walls[J]. Renewable and Sustainable Energy Reviews, 2011, 15(1): 379-391.

[7]. Chintakrinda K, Weinstein R D, Fleischer A S. A direct comparison of three different material enhancement methods on the transient thermal response of paraffin phase change material exposed to high heat fluxes[J]. International Journal of Thermal Sciences, 2011, 50(9): 1639-1647.

[8]. Yang Z, Garimella S V. Melting of phase change materials with volume change in metal foams[J]. Journal of Heat Transfer, 2010, 132(6): 062301.

[9]. Fukai J, Kanou M, Kodama Y, et al. Thermal conductivity enhancement of energy storage media using carbon fibers[J]. Energy Conversion and Management, 2000, 41(14): 1543-1556.

[10]. Zhong Y, Guo Q, Li S, et al. Heat transfer enhancement of paraffin wax using graphite foam for thermal energy storage[J]. Solar Energy Materials and Solar Cells, 2010, 94(6): 1011-1014. 